\title{
Pengaruh Persepsi Konsumen terhadap Keputusan Pembelian Bibit Ayam Murung Panggang di Desa Murung Panggang
}

\section{(Influence of Consumer Perceptions to Purchase Decision of Chicken Seeds Murung Panggang in Murung Panggang Village)}

\author{
Novia Sari ${ }^{1)}$, Azwar Saihani' ${ }^{2)}$ dan Rum Van Royensyah ${ }^{3)}$ \\ Program Studi Agribisnis, Sekolah Tinggi Ilmu Pertanian Amuntai \\ ${ }^{1)}$ noviasariii89@gmail.com \\ 2)Azwar.saihani63@yahoo.com \\ ${ }^{3)}$ Vanroyensyah61@gmail.com
}

\begin{abstract}
ABSTRAK
Penelitian ini bertujuan untuk mengidentifikasi persepsi konsumen bibit ayam murung panggang dan mengetahui pengaruh dari persepsi konsumen dalam pengambilan keputusan pembelian bibit ayam murung panggang di Desa Murung Panggang Kecamatan Amuntai Selatan. Berdasarkan hasil penjumlahan nilai skala likert bahwa nilai rata-rata skor pernyataan persepsi secara keseluruhan adalah 100,9 yaitu berada pada daerah setuju. Berdasarkan hasil analisis koefisien determinasi $\left(R^{2}\right)$ dari persamaan regresi secara keseluruhan terdapat pengaruh variabel independen meliputi variabel harga, variabel kualitas, dan variabel pelayanan produsen terhadap keputusan pembelian yang dapat dilihat pada nilai adjusted $R$ Square yaitu 0,644. Dari hasil uji t faktor harga tidak berpengaruh nyata terhadap keputusan pembelian dengan nilai signifikan adalah 0,782 >0,05, Sehingga Ho ditolak dan $\mathrm{H}_{1}$ diterima. Faktor kualitas tidak berpengaruh nyata terhadap keputusan pembelian dengan nilai signifikan 0,053 > 0,05 sehingga $\mathrm{H}_{0}$ diterima dan $\mathrm{H}_{1}$ ditolak dan faktor tingkat pelayanan produsen berpengaruh nyata terhadap keputusan pembelian dengan nilai signifikan adalah $0,000<0,05$, sehingga $\mathrm{H}_{0}$ ditolak dan $\mathrm{H}_{1}$ diterima.
\end{abstract}

Kata kunci: Persepsi, keputusan, pembelian, variabel, faktor.

\section{ABSTRACT}

This study aims to identify consumer perceptions of roasted broiled chicken seeds and determine the effect of consumer perceptions in making decisions to purchase roasted mulberry chicken seeds in Murung Panggang Village, South Amuntai District. Based on the sum of the Likert scale values that the average score of the overall perception statement is 100.9, which is in the area agreed. Based on the results of the coefficient of determination analysis $\left(R_{2}\right)$ of the regression equation as a whole there are influences of independent variables including price variables, quality variables, and producer service variables on purchasing decisions that can be seen in the adjusted $R$ Square value of 0.644. From the results of the t-test, the price factor does not significantly influence the purchasing decision with a significant value of 0.782>0.05, so $H_{0}$ is rejected, and $H_{1}$ is accepted. Quality factors have no significant effect on purchasing decisions with a significant value of $0.053>0.05$ so that $H_{0}$ is accepted and $H_{1}$ is rejected, and factor levels of producer service have a significant effect on purchasing decisions with a significant value of $0,000<0.05$, so $H_{0}$ is rejected and $H_{1}$ is accepted.

Keywords: Perception, decision, purchase, variable, factor.

\section{PENDAHULUAN}

Pembangunan peternakan pada abad 21 dirancang mempunyai prospek yang baik karena diperkirakan dalam beberapa tahun kedepan produksi ternak dalam negeri masih dibawah permintaan pasar (konsumen). Pengembangan peternakan berperan besar dalam pembangunan pertanian, baik dalam aspek penyediaan, pangan, penyerapan tenaga kerja, pengentasan kemiskinan maupun aspek kelestarian lingkungan hidup (Rukmana, 2003).

Kabupaten Hulu Sungai Utara dengan mayoritas lahan berupa rawa mempunyai potensi yang sangat besar untuk pengembangan peternakan unggas, salah satunya adalah peternakan ayam lokal. 
Ayam lokal asli dari kabupaten Hulu Sungai Utara adalah ayam murung panggang. ayam murung pangang yang dibudidayakan dan dibesarkan, karena bibit ayam murung panggang daya tahan tubuhnya lebih kuat. Bibit ayam murung panggang juga tingkat penjualannya tiap tahunnya meningkat. Bahkan persepsi konsumen tehadap keputusan pembelian bibit ayam murung panggang ini akan meningkatkan penjualan. Dalam pemasaran, persepsi konsumen merupakan sesuatu yang penting. Tindakan dan perilaku pembelian konsumen didasarkan pada persepsi mereka, bukan pada realitas objektif yang ada. Persepsi ini dipengaruhi oleh kebutuhan, keinginan, nilai, dan pengalaman pribadi masng-masing individu (Schifman dan Kanuk, 2007). Tujuan penelitian ini adalah untuk (i) mengetahui persepsi konsumen terhadap bibit ayam murung panggang, (ii) mengetahui pengaruh persepsi konsumen terhadap atribut (harga bibit, kualitas bibit, dan pelayanan produsen).

\section{METODE PENELITIAN}

Penelitian ini dilaksanakan di Desa Murung Panggang Kecamatan Amuntai
Selatan Kabupaten Hulu Sungai Utara Provinsi Kalimantan Selatan pada bulan Maret - Mei 2018. Data yang digunakan dalam penelitian ini adalah dengan data primer dan sekunder. Metode pengumpulan data dalam penelitian ini dilakukan dengan non-probability sampling, yang ada dimana teknik pengambilan sampel yang digunakan adalah Accidental sampling, yaitu metode sampel dengan melakukan mengumpulkan data melalui siapa saja yang ditemui, dalam hal ini adalah konsumen yang membeli bibit ayam murung panggang. jumlah responden adalah 25 konsumen dengan 20 prtanyaan. Analisis data yang digunakan yang pertama analisis kualitatif yaitu dengan menggunakan skala likert dan setelah itu data tersebut dikuantitatifkan dengan menggunakan uji hipotesis yaitu Koefisien Determinasi $\left(\mathrm{R}^{2}\right)$ dan uji t (Parsial) dengan menggunakan SPSS versi 20.

\section{HASIL DAN PEMBAHASAN}

\section{Hasil}

\section{Persepsi Konsumen Harga Terhadap Keputusan Pembelian}

Tabel 1. Skor Rata-Rata Responden Konsumen Terhadap Keputusan Pembelian Berdasarkan Variabel Harga

\begin{tabular}{ccc}
\hline Indikator & No pernyataan & Skor \\
\hline \multirow{3}{*}{ Variabel Harga } & 1 & 77 \\
& 2 & 102 \\
& 3 & 106 \\
& 4 & 59 \\
\hline & Jumlah & 344 \\
\hline & Rata-Rata & 86 \\
\hline
\end{tabular}

Sumber : Pengolahan data primer (2018).

Secara kontinum persepsi konsumen pada variabel harga terhadap keputusan pembelian bibit ayam murung panggang,

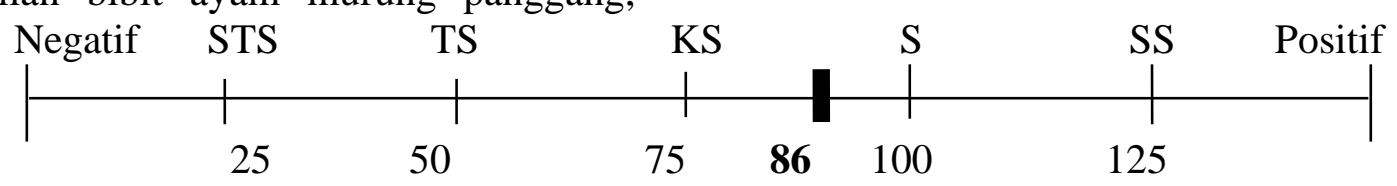

Berdasarkan penggambaran kontinum maka dapat dilihat bahwa variabel harga pada keputusan pembelian konsumen di daerah dapat dilihat dari penggambaran sebagai berikut : kurang setuju, karena harga tidak terlalu mempengaruhi keinginan konsumen untuk membeli bibit ayam murung panggang. 
Harga bukan pertimbangan yang penting bagi konsumen karena konsumen yang membeli bibit adalah peternak yang melakukan usaha pembesaran dari ayam murung panggang tersebut.

\section{Persepsi Konsumen Kualitas Terhadap Keputusan Pembelian}

Tabel 2. Skor Rata-Rata Responden Konsumen Terhadap Keputusan Pembelian Berdasarkan Variabel Kualitas

\begin{tabular}{ccc}
\hline Indikator & No pernyataan & Skor \\
\hline \multirow{3}{*}{ Variabel Kualitas } & 1 & 105 \\
& 2 & 103 \\
& 3 & 117 \\
& 4 & 117 \\
\hline & Jumlah & 442 \\
\hline & Rata-Rata & 110,5 \\
\hline
\end{tabular}

Sumber : Pengolahan data primer (2018).

Secara kontinum persepsi konsumen pada variabel kualitas terhadap keputusan pembelian bibit ayam murung panggang, dapat dilihat dari penggambaran sebagai berikut

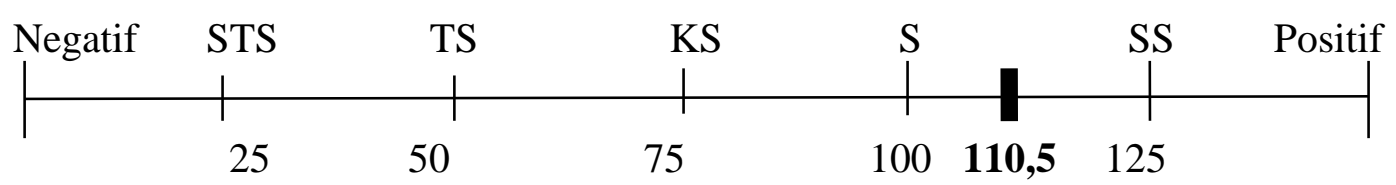

Berdasarkan penggambaran kontinum maka dapat dilihat bahwa variabel kualitas pada keputusan pembelian konsumen di daerah setuju, karena kualitas mempengaruhi keinginan konsumen untuk membeli bibit ayam murung panggang. Pada dasarnya

\section{Persepsi Konsumen Pelayanan Produsen} Terhadap Keputusan Pembelian

Tabel 3. Skor Rata-Rata Responden Konsumen Terhadap Keputusan Pembelian Berdasarkan Variabel Pelayanan Produsen

\begin{tabular}{ccc}
\multicolumn{2}{l}{ Variabel Pelayanan Produsen } \\
\hline Indikator & No pernyataan & Skor \\
\hline Variabel & 1 & 102 \\
Pelayanan & 2 & 109 \\
Produsen & 3 & 111 \\
& 4 & 106 \\
& 5 & 109 \\
\hline \multicolumn{3}{c}{ Rumlah } \\
Rata-Rata & 105 \\
\hline Sumber : Pengolahan data primer $(2018)$ & 642 \\
\hline
\end{tabular}

Sumber : Pengolahan data primer (2018).

Secara kontinum persepsi konsumen pada variabel pelayanan produsen terhadap jenis ayam murung panggang ini memiliki kualitas yang khas dan daya tahan tubuh yang lebih kuat dari jenis ayam lainnya yang membuat menarik minat konsumen untuk membeli bibit ayam murung panggang. 
keputusan pembelian bibit ayam murung sebagai berikut :

panggang, dapat dilihat dari penggambaran

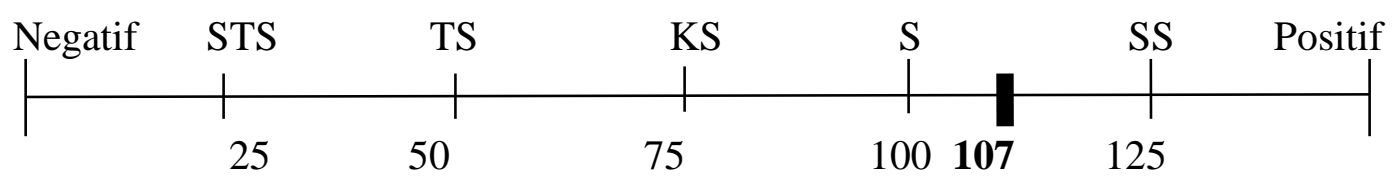

Berdasarkan penggambaran kontinum maka dapat dilihat bahwa variabel pelayanan ayam murung panggang. Pelayanan produsen sangat penting bagi suatu produsen pada keputusan pembelian konsumen di daerah setuju, karena pelayanan produsen mempengaruhi penjualan, jika pelayanan suatu produsen baik maka konsumen ingin kembali lagi keinginan konsumen untuk membeli bibit untuk membeli.

Tabel 4. Skor Rata-Rata Responden Konsumen Terhadap Keputusan Pembelian Berdasarkan Semua Variabel

\begin{tabular}{ccc}
\hline Indikator & No pernyataan & Skor \\
\hline & 1 & 77 \\
2 & 102 \\
3 & 106 \\
Persepsi & 4 & 59 \\
Konsumen & 5 & 105 \\
& 6 & 103 \\
& 7 & 117 \\
& 8 & 117 \\
& 9 & 114 \\
& 10 & 76 \\
& 11 & 102 \\
& 12 & 109 \\
& 13 & 111 \\
& 14 & 106 \\
& 15 & 109 \\
& 16 & 105 \\
& 17 & 102 \\
& 18 & 105 \\
& 19 & 101 \\
& 20 & 92 \\
\hline Jumlah & 2018 \\
\hline Rata-rata & 100,9 \\
\hline
\end{tabular}

Sumber : Pengolahan data primer (2018).

Secara kontinum persepsi konsumen pada keputusan pembelian pada variabel harga, variabel kualitas, dan variabel pelayanan produsen pada keputusan pembelian bibit ayam murung panggang, dapat dilihat pada penggambaran sebagai berikut :

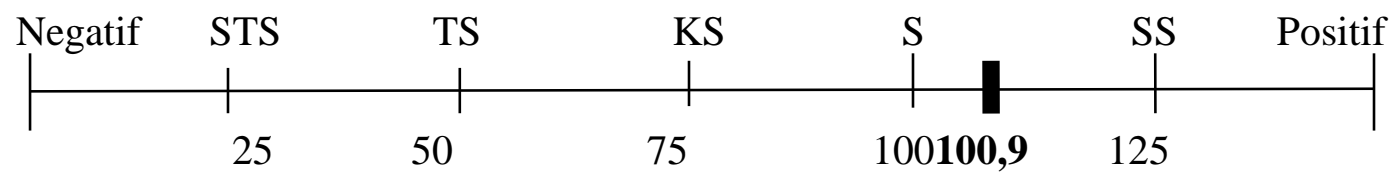


Hasil analisis skala likert pada persepsi konsumen terhadap keputusan pembelian bibit ayam murung panggang di Desa Murung Panggang Kecamatan Amuntai Selatan, berdasarkan hasil penjumlahan nilai skala likert pada semua indikator pernyataan mengenai persepsi konsumen terhadap keputusan pembelian bibit ayam murung panggang, maka pemggambaran kontinum jelas terlihat bahwa nilai rata-rata skor pernyataan persepsi secara keseluruhan adalah 100,9 yaitu berada pada daerah setuju. Jadi persepsi konsumen terhadap keputusan pembelian bibit ayam murung panggang di Desa Murung Panggang Kecamatan Amuntai Selatan adalah setuju.

\section{Pengaruh Persepsi Konsumen Terhadap}

\section{Keputusan Pembelian}

\section{Koefisien Determinasi $\left(\mathbf{R}^{2}\right)$}

Koefisien ini digunakan untuk mengetahui besarnya variasi variabel terikat (Y) dapat diterangkan oleh variasi varabel bebas $(\mathrm{X})$, dilihat dari nilai $\mathrm{R}^{2}$ yang diperoleh $\mathrm{R}^{2}$ disebut juga koefisien atau indeks determinasi yang mengukur derajat hubungan regresi (Sarwoko, 2010). Nilai koefisien deerminasi $\left(\mathrm{R}^{2}\right)$ pada faktor-faktor yang mempengaruhi konsumen dalam keputusan pembelian (Tabel 5).

Tabel 5. Koefisien Determinasi

\begin{tabular}{llrrr}
\hline Model & $\mathrm{R}$ & $\mathrm{R}$ Square & Adjusted R Square & Std. Error of the Estimate \\
\hline 1 &, $830^{\mathrm{a}}$ &, 688 &, 644 &, 64469 \\
\hline
\end{tabular}

Sumber : Pengolahan data primer (2018).

Berdasarkan tabel diatas hasil yang diperoleh dalam koefisien determinasi yang telah disesuaikan (Adjusted R2), yaitu sebesar 0,644, nilai tersebut diubah di ubah dalam bentuk persen, yang berarti $64,4 \%$ yaitu presentasi sumbangan pengaruh variabel harga, kualitas, dan pelayanan produsen terhadap keputusan pembelian bibit ayam murung panggang. hal ini berarti bahwa variabel bebas dapat menjelaskan variabel tingkat sebesar $64,4 \%$ sedangkan sisanya $35,6 \%$ dipengaruhi oleh variabel lain yang tidak diteliti.

\section{Uji t (Parsial)}

Uji t adtalah uji yang digunakan oleh para ahli ekonometrika untuk menguji tentang koefisien-koefisien regresi secara individual. Uji t mudah digunakan karena menjelaskan perbedaan unit pengukuran variabel-variabel dan deviasi standar dari koefisien-koefisien yang estimasi. Hasil uji $\mathrm{t}$ akan dapat diketahu apakah faktor-faktor yang mempengaruhi seperti harga, kualitas, dan pelayanan produsen berpengaruh atau tidak terhadap keputusan pembelian (Tabel $6)$.

Tabel 6. Uji t (Parsial)

\begin{tabular}{rlrr}
\hline Model & \multicolumn{1}{c}{ T } & \multicolumn{1}{c}{ Sig } \\
\hline \multirow{4}{*}{1} & (Constant) & 3,643 &, 002 \\
& Harga &,- 280 &, 782 \\
& Kualitas & $-2,054$ &, 053 \\
& Pelayanan & 6,579 &, 000 \\
\hline
\end{tabular}

Sumber : Pengolahan data primer (2018).

Hasil uji menyatakan bahwa nilai t hitung variabel harga lebih kecil daripada $t$ tabel 2,073 artinya tidak berpengruh signifikan terhadap keputusan pembelian, sehingga $\mathrm{H}_{0}$ diterima dan $\mathrm{H}_{1}$ ditolak, variabel kualitas nilai $\mathrm{t}$ hitung lebih kecil daripada $\mathrm{t}$ tabel
2,073 artinya tidak berpengruh signifikan terhadap keputusan pembelian, sehingga $\mathrm{H}_{0}$ diterima dan $\mathrm{H}_{1}$ ditolak, sedangkan variabel pelayanan produsen nilai t hitung lebih besar daripada t tabel 2,073 artinya berpengaruh 
signifikan terhadap keputusan pembelian, sehingga $\mathrm{H}_{0}$ ditolak dan $\mathrm{H}_{1}$ diterima.

\section{Pembahasan}

Berdasarkan hasil penelitian dimana hasil dari penskalaan likert terlihat nilai ratarata dengan tiga variabel yaitu variabel harga sebesar 86 yang berada di daerah kurang setuju, variabel kualitas sebesar 110,5 yang berada di daerah setuju dan variabel pelayanan produsen sebesar 107 yang berada di daerah setuju. Berdasarkan hasil penskalaan likert maka variabel yang paling tinggi nilainya adalah variabel kualitas, alasan konsumen membeli bibit ayam murung panggang karena bibit ayam murung panggang ini memiliki daya tahan tubuh yang kuat dan juga pelayanan produsen yang baik pada konsumen. Pada hasil pengujian koesioner dengan uji validitas dan reliabilitas semua pernyataan koesioner dinyatakan valid dan reliabel. Koefisien determinasi tentang persepsi konsumen terhadap keputusan pembelian bibit ayam murung panggang dengan tiga variabel yaitu harga $\left(\mathrm{X}_{1}\right)$, kualitas $\left(\mathrm{X}_{2}\right)$, dan pelayanan produsen $\left(\mathrm{X}_{3}\right)$ memiliki nilai 0,644 menunjukkan bahwa faktor yang mempengaruhi konsumen dalam keputusan pembelian bibit ayam murung panggang sebesar 64,4\%, sedangkan uji $t$ (parsial) variabel harga $\left(\mathrm{X}_{1}\right)$ dan kualitas $\left(\mathrm{X}_{2}\right)$ tidak bepengaruh nyata terhadap keputusan pembelian (Y) dan variabel pelayanan produsen $\left(\mathrm{X}_{3}\right)$ berpengaruh nyata terhadap keputusan pembelian (Y).

\section{KESIMPULAN}

Nilai skor rata-rata dari konsumen adalah 100,9 pada garis kontinum berada pada daerah setuju, itu berarti bahwa persepsi konsumen adalah setuju. Hasil analisis regresi nilai koefisien determinasi $\left(\mathrm{R}^{2}\right)$ dari persamaan regresi secara keseluruhan terdapat pengaruh variabel independen meliputi harga, kualitas, dan pelayanan produsen yang dapat dilihat pada nilai adjusted $\mathrm{R}$ square yaitu 0,644 atau $64,4 \%$, Sedangkan dar uji t faktor yang berpengaruh nyata terhadap keputusan pembelian adalah faktor pelayanan produsen sedangkan yang tidak berpengaruh nyata adalah faktor harga dan kualitas.

\section{DAFTAR PUSTAKA}

Nazir, M. 2005. Metode Penelitian Edisi 6. Ghalia Indonesia. Bogor.

Rukmana, R. 2003. Beternak Kerbau Potensi dan Analisis Usaha. Aneka Ilmu, Semarang.

Sarwoko. 2010. Dasar-Dasar Ekonometrika. Penerbit Andi. Yogyakarta.

Schiffman, L.G. dan Kanuk Leslie Lazar. 2007. Perilaku Konsumen Edisi 7. PT Indeks. Jakarta. 